\title{
Association of Lactation Period and Maternal Body Mass Index with Breast Milk Macronutrient Content of West Sumatera Breastfeeding Mothers
}

\author{
Gustina Lubis ${ }^{1}$, Fitrisia Amelin ${ }^{2}$ \\ \{fitrisiaamelin@med.unand.ac.id ${ }^{1}$ \} \\ Department of Child Health, Faculty of Medicine, Universitas Andalas/ Dr. M.Djamil General \\ Hospital, Padang, Indonesia
}

\begin{abstract}
Early complementary foods in breastfed infant usually emerged by maternal perception of insufficient milk supply, breast milk content and maternal body composition. This early cessation will be affected to non-exclusive breastfeeding in first 6 months. In Indonesia, studies on breast milk were limited. Measurement of sufficient breast milk content and its correlation to maternal body mass index (BMI) aimed in this study to improve maternal confidence in maintaining exclusive breastfeeding. A cross-sectional study was conducted in several Public Health Centre in Padang, West Sumatera. Breast milk of mid-feed expression of one side breast from 145 breastfeeding mothers at 17-210 days postpartum was collected at 9:00 a.m. to 11:00 a.m. Total energy was analyzed using a MIRIS ${ }^{\circledR}$ human milk analyzer, which was based on a mid-infrared transmission spectroscopy technique. We measured the weight and height of mothers for calculating BMI. Statistical analyses were carried out using statistical software. A p-value $<0.05$ was considered as statistically significant. Breast milk energy was $67,21+11,76 \mathrm{kcal} / \mathrm{dl}$. The mean maternal BMI was $24.17+6,35 \mathrm{~kg} / \mathrm{m} 2$. There was no significant association between lactation period with breast milk energy, fat, carbohydrate and protein content. $(\mathrm{p}=0.486$, $\mathrm{p}=0.137, \mathrm{p}=0.712, \mathrm{p}=0.338$, respectively). There was no significant association between breast milk energy, fat, carbohydrate, and protein content to maternal BMI. ( $p=0,568$, $\mathrm{p}=0,115, \mathrm{p}=0.095, \mathrm{p}=0,150$, respectively). Breast milk content was constant during seven months of the lactation period. Breast milk content was not associated with maternal BMI.
\end{abstract}

Keywords: Breastfeeding, Breast Milk, Breastmilk Expression, Lactation, Macronutrient.

\section{Introduction}

Breastfeeding was the ideal and oldest method in infants and children feeding and promoting the optimal growth and development.[1] World Health Organization (WHO), United Nations International Children's Emergency Fund (UNICEF) and American Academy of Pediatrics (AAP) recommend exclusive breastfeeding for 6 months (180 days) and start complementary feeding from the age of 6 months with continued breastfeeding up to 2 years of age or beyond for optimal infant feeding. [1],[2] Breast milk contains macronutrients (carbohydrates, many complex proteins, and lipid), micronutrients, hormones, antibodies, bioactive molecules, and cells.[3],[4] The composition of breast milk is dynamic and varies. Influences on compositional differences include time of lactation, length of gestation, maternal diseases, genotype, and diet.[5],[6] 
Early complementary foods in breastfed infant usually emerged by the maternal perception of insufficient milk supply (PIM).[7] Mothers believe that breast milk content and the amount was insufficient.[8] More than half breastfeeding mother in Belgium said shorter breastfeeding duration because of PIM.[7] Maternal body mass index (BMI) in some studies became maternal body compositions indicator that influenced breast milk content. Maternal BMI was associated with fat content in Chinese breast milk mothers,[9] whereas Filipino mothers lacked association between maternal BMI and breast milk content. [10]

The early cessation of breastfeeding will affect to non-exclusive breastfeeding in 6 months. In Indonesia, studies on breast milk are limited. Measurement of sufficient breast milk energy and the correlation to maternal body mass index (BMI) will improve maternal confidence in maintaining exclusive breastfeeding. This study investigated the relationship between lactation period and maternal body mass index (BMI) with breast milk energy, fat, protein, and carbohydrate content.

\section{Methods}

A cross-sectional study was conducted in the Public Health Center in Padang, West Sumatera. The sample of the study recruited 145 breastfeeding mothers at the mature milk stage (15-210 postpartum days). Medical Ethics Committee of Andalas University approved the ethical study clearance.

\subsection{Anthropometric data}

Weight and height were measured with the subjects barefoot and wearing light clothing, by using a scale (range $0.1-150 \mathrm{~kg}$ ) and a tape measure (range 0-200 $\mathrm{cm}$ ). Body mass index (BMI) $\left(\mathrm{kg} / \mathrm{m}^{2}\right)$ was thus calculated.

\subsection{Milk sampling}

From the interview, almost all mothers breastfed their infant around 6 a.m. Breast milk of midfeed expression of one side breast days postpartum was collecting at 9:00 a.m. to 11:00 a.m. Last time infant breastfed was three hours before expression. Mother breastfed the baby about 3-5 minute and then change to other breasts, while the first breast was manually expressed for sampling in order to get fore and hindmilk.[10] Breast milk volume that collected by manual hand expression was $15 \mathrm{~mL}$. Samples transport by coolbox temperature about $-10^{0}-4^{0} \mathrm{C}$ measured directly after collecting on the same day. Sample homogenized before measurement for representing the true composition of the milk sample. The MIRIS Human Milk Analyzer (Uppsala, Sweden) was used to analyze the composition of breast milk for the content of energy, carbohydrate, protein, and fat, which is based on a mid-infrared transmission spectroscopy technique.

\subsection{Statistical Analysis}

All statistical calculations were performed with SPSS statistical software. Normality test was performed using the Kolmogorov-Smirnov test. Results with normal distributions are presented as mean and standard deviation (SD). Anova test was used to analyze the correlation between 
breast milk composition according to the lactation period, and the correlation between maternal BMI with breast milk energy, fat, carbohydrate, and protein. Statistically significant differences were determined at p-value of less than 0.05.

\section{Results}

Characteristics of 145 subject are summarized in Table 1. Maternal BMI was in normal range $(24.17 \pm 6.355)$ which is consists of underweight $6,21 \%$, normal $63,45 \%$, overweight $19,31 \%$ and obese $11,03 \%$.

Table 1. Characteristics of Breastfeeding Mothers and Infant

\begin{tabular}{ll}
\hline Variables & Mean $\pm \mathrm{SD}$ \\
\hline Breastfeeding Mothers & \\
Age & $29.50 \pm 4.705$ \\
Height & $153.28 \pm 5.428$ \\
Weight & $55.89 \pm 11.107$ \\
BMI & $24.17 \pm 6.355$ \\
& \\
Infant & \\
Age & $128.79 \pm 41.216$ \\
& \\
Breast milk content & \\
Energi (kcal/dL) & $67.21 \pm 11.758$ \\
Fat (g/dL) & $4.02 \pm 1.616$ \\
Carbohydrate (g/dL) & $5.75 \pm 0.785$ \\
Protein (g/dL) & $1.05 \pm 0.488$ \\
\hline
\end{tabular}

Breast milk macronutrient content from the lactation period are shown in Table 2. Energy, fat, protein, and carbohydrate contents $(\mathrm{p}=0.486, \mathrm{p}=0.137, \mathrm{p}=0.338, \mathrm{p}=0.712$, respectively). Contents were not significantly different among period. Energy in 0-30 day and 31-60 day lower than the period after, but no difference. The range of fat and protein value also lower in $0-30$ day than the period after that, but not significantly different.

Table 2. Breast Milk Macronutrient Content according to the Lactation Period

\begin{tabular}{ccccccccc}
\hline \multirow{2}{*}{$\begin{array}{c}\text { Lactation } \\
\text { period } \\
\text { (day) }\end{array}$} & \multicolumn{2}{c}{ Energy $(\mathrm{kcal} / \mathrm{dl})$} & \multicolumn{2}{c}{ Fat $(\mathrm{g} / \mathrm{dl})$} & \multicolumn{2}{c}{ Carbohydrate $(\mathrm{g} / \mathrm{dl})$} & \multicolumn{2}{c}{ Protein $(\mathrm{g} / \mathrm{dl})$} \\
\cline { 2 - 8 } & Mean \pm SD & Range & Mean \pm SD & Range & Mean \pm SD & Range & Mean \pm SD & Range \\
\hline $\mathbf{0 - 3 0}$ & $61.33 \pm 5.686$ & $47.21 \pm 75.46$ & $3.60 \pm 0.854$ & $1.48 \pm 5.72$ & $5.47 \pm 0.153$ & $5.09 \pm 5.85$ & $1.33 \pm 0.462$ & $0.19 \pm 2.48$ \\
$\mathbf{3 1 - 6 0}$ & $62.38 \pm 9.211$ & $54.67 \pm 70,08$ & $2.83 \pm 0.932$ & $2.05 \pm 3.60$ & $5.78 \pm 0.570$ & $5.30 \pm 6.25$ & $1.18 \pm 0.260$ & $0.96 \pm 1.39$ \\
$\mathbf{6 1 - 9 0}$ & $69.00 \pm 6.403$ & $63.08 \pm 74.92$ & $3.39 \pm 1.163$ & $2.31 \pm 4.46$ & $5.57 \pm 0.680$ & $4.94 \pm 6.20$ & $1.31 \pm 0.537$ & $0.82 \pm 1.81$ \\
$\mathbf{9 1 - 1 2 0}$ & $68.03 \pm 11.084$ & $64.33 \pm 71.72$ & $3.99 \pm 1.197$ & $3.59 \pm 4.39$ & $5.74 \pm 0.779$ & $5.48 \pm 6.00$ & $1.10 \pm 0.535$ & $0.92 \pm 1.28$ \\
$\mathbf{1 2 1 - 1 5 0}$ & $66.22 \pm 12.230$ & $62.31 \pm 70.14$ & $3.96 \pm 1.531$ & $3.47 \pm 4.44$ & $5.92 \pm 0.290$ & $5.83 \pm 6.02$ & $0.92 \pm 0.311$ & $0.82 \pm 1.02$ \\
$\mathbf{1 5 1 - 1 8 0}$ & $69.78 \pm 13.608$ & $65.25 \pm 74.32$ & $4.55 \pm 2.198$ & $3.81 \pm 5.28$ & $5.69 \pm 0.861$ & $5.40 \pm 5.98$ & $1.05 \pm 0.512$ & $0.88 \pm 1.22$ \\
$\mathbf{1 8 1 - 2 1 0}$ & $63.92 \pm 10.484$ & $57.59 \pm 70.26$ & $4.01 \pm 1.232$ & $3.26 \pm 4.75$ & $5.55 \pm 1.567$ & $4.60 \pm 6.49$ & $1.06 \pm 0.737$ & $0.62 \pm 1.51$ \\
p-value & \multicolumn{2}{c}{0.486} & 0.137 & & 0.712 & & 0.338 \\
\hline
\end{tabular}


Association among maternal BMI and breast milk energy, fat, carbohydrate, and protein are shown in Table 3. We found no significant correlation between breast milk energy, fat, carbohydrate, and protein content to maternal BMI ( $p=0.568, p=0.115, p=0.095, p=0.150$, respectively).

Table 3. The relationship between BMI and Breast Milk Energy

\begin{tabular}{llllll}
\hline \multicolumn{1}{c}{ BMI } & $\mathrm{N}$ & Energy & Fat & Carbohydrate & Protein \\
& $(145)$ & Mean $\pm \mathrm{SD}$ & Mean $\pm \mathrm{SD}$ & Mean $\pm \mathrm{SD}$ & Mean $\pm \mathrm{SD}$ \\
\hline Underweight & 9 & $68.33 \pm 8.185$ & $4.00 \pm 1.216$ & $5.17 \pm 1.273$ & $1.40 \pm 0.612$ \\
Normal & 92 & $66.23 \pm 11.233$ & $3.83 \pm 1.365$ & $5.81 \pm 0.694$ & $1.01 \pm 0.385$ \\
Overweight & 28 & $68.32 \pm 13.687$ & $4.68 \pm 2.388$ & $5.66 \pm 0.952$ & $1.08 \pm 0.696$ \\
Obese & 16 & $70.25 \pm 13.036$ & $3.98 \pm 1.299$ & $5.89 \pm 0.491$ & $1.07 \pm 0.476$ \\
p-value & & 0.568 & 0.115 & 0.095 & 0.150 \\
\hline
\end{tabular}

\section{Discussion}

This study of 145 lactating mothers is the largest report describing breast milk macronutrient in Indonesia. The mean of maternal age in this study was $29.50 \pm 4.705$ years which is an ideal productive age. Maternal BMI was $24.17 \pm 6.355$ and more than a half with normal nutritional status. Mean of infant age was 128.79 \pm 41.216-day range from 17-210 days regarded breastfed mature milk. Mature milk was higher content of lactose compared to colostrum which higher of protein content.[9]

This study presented the value of breast milk content about $67.21 \pm 11.75 \mathrm{kcal} / \mathrm{dL}$ for energy, $4.02 \pm 1.616 \mathrm{~g} / \mathrm{dL}$ for fat, $5.75 \pm 0.785 \mathrm{~g} / \mathrm{dL}$ for carbohydrate and $1.05 \pm 0.488$ for protein. Breast milk content was in normal range compared to some studies $(60-88 \mathrm{kcal} / \mathrm{dL}$ for energy, 2.5-6.0 $\mathrm{gr} / \mathrm{dL}$ for fat, 6.3-8.1 g/dL for carbohydrate and 0.83-1.30 g/dL for protein).[11] Conversely, fat content in this study more higher might be caused by Minangkabau ethnic consumption pattern in West Sumatera with high fat intake (30.2\% of all intake).[12] The previous study has shown that the variation of the fat content of breast milk related to maternal intake.[13] Villalpando et al. summarized that fat intake were not related to breast milk fat content. [14] The variation also depend on hindmilk or foremilk, and frequency of breastfeeding. [15],[16]. The lower range of carbohydrate might be caused by higher fat content and by mid-feed sampling with deep latch infant feed, will affect to more milk consumption, so that breast milk more likely hindmilk.

Another study about maternal age and colostrum composition found that colostrum fat content of older mothers ( $\geq 35$ years) is much higher than that of younger. This possibility caused by increasing fat synthesis and excretion in breast milk reduced the water content of milk or a combination of both.[17] All sample in this was below 35 years so that no comparison based on maternal age.

Lactation period plays an important role in the nutrient content of breast milk. Numerous studies about the protein content of breast milk presented a reduction in protein over the first year of lactation.[4],[18] In this study, we did not find any significant correlation between lactation period with breast milk energy, fat, protein, and carbohydrate content $(\mathrm{p}=0.486$, $\mathrm{p}=0.137, \mathrm{p}=0.338, \mathrm{p}=0.712$, respectively). To compare with studies in Chinese mothers, found the individual variable in fat content based on lactation period, but lactose content was constant from 1-8 months.[9] 
In this study, there was no significant correlation between maternal BMI and breast milk energy $(p=0.568)$. Chang et al. study found that maternal BMI was positively associated with the breast milk content of energy, lipid, and protein, but negatively associated with carbohydrates (lactose).[19] There also no significant correlation between maternal BMI and macronutrient content (fat, carbohydrate, and protein content, $p=0.115, p=0.095, p=0.150$, respectively). In Chinese mother study, maternal BMI was positively associated with breast milk fat content and protein content, but negatively to carbohydrate.[9] Mandel et al., found that the fat content of breast milk was not influenced by maternal BMI.[20] Conversely, Nikniaz et al., found a significant association between maternal BMI and fat content of breast milk $(p=0.02) \cdot[21]$

\section{Conclusion}

Breast milk energy was constant during seven months of the lactation period. The maternal perception of decreased supply and breast milk content after 4 months lactation period is indisputable by this study. Breast milk composition was not associated with maternal BMI. A large study in Indonesia about contributing factors to breast milk macronutrient content is needed in the further investigation.

\section{References}

[1] Meek JY, Hatcher AJ.: The Breastfeeding-friendly pediatric office practice. American Academy of Pediatrics. Vol.139(5), pp.1-9 (2017)

[2] WHO : Infant and young child feeding: Model Chapter for textbooks for medical students and allied health professionals. WHO Library Cataloguing-in-Publication Data, pp 3-4 (2009)

[3] Andreas NJ, Le-Doare KM.: Human breast milk: A review on its composition and bioactivity. Elsevier.Vol.91(11), pp. 629-35 (2015)

[4] Lonnerdal,B.: Breast milk: A truly functional food. Nutrition.Vol.16, pp 509-11(2000)

[5] Ballard O, Morrow AL.: Human milk composition. Nutrients and Bioactive Factors. National Institute of Health. Elsevier. pp.1-19 (2012)

[6] Mosca F, Gianni ML.: Human milk: Composition and health benefits. Medical and Surgical Pediatrics.Vol.39(155). pp. 47-52 (2017)

[7] Robert E, Coppieters Y, Swennen B, Dramaix M.: The reasons for early weaning, perceived insufficient breast milk, and maternal dissatisfaction: comparative studies in two belgian regions. Int Sch Res Notices. Vol 2014. pp 6-7

[8] McCarter-Spaulding DE, Kearney MH. Parenting self efficacy and perception of insufficient breast milk. J. Obstet. Gynecol. Neonatal Nurs. Vol 30(5). pp. 515-522 (2001)

[9] Titi Y, Yumei Z, Yibing N, Lili Y, Defu M, Yingdong Z, et al.: Breast milk macronutrient composition and the associated factors in urban Chinese mothers. Chinese Med J Peking. Vol 127 (9). pp. 1723-1724 (2014)

[10] Quinn EA, Largado F, Power M, K Christopherw. Predictors of breast milk macronutrient composition in Filipino mothers. Am J Hum Biol. pp. 5-7 (2012)

[11] Miller EM, Aiello MO, Fujita M, Hinde K, Miligan L, Quinn EA.: Field and laboratory methods in human milk research. Am J Hum Biol. Vol 2. pp 1-11 (2013).

[12] Djuwita R., Purwiyantyastuti., Kamso S.: Nutrient intake pattern of a Minangkabau ethnic group. Mekara Kesehatan. Vol 7(1), pp 8 (2003)

[13] Innis SM. Human milk and formula fatty acids. J Pediatr.;Vol.120,pp.S56-61 (1992) 
[14] Villalpando S., Prado M.,: Interrealtion among dietary energy and fat intakes, maternal body fatness, and milk total lipid in human. J Mammary Gland Bio and Neoplasma. Vol 4(3), pp.288(1999)

[15] Mitoulas LR, Kent JC, Cox DB, Owens RA, Sherriff JL, Hartmann PE. Variation in fat, lactose and protein in human milk over $24 \mathrm{~h}$ and throughout the first year of lactation. $\mathrm{Br} \mathrm{J}$ Nutr.Vol.88,pp.29-37(2002)

[16] Kent JC, Mitoulas LR, Cregan MD, Ramsay DT, Doherty DA, Hartmann PE. Volume and frequency of breastfeeding and fat content of breast milk throughout the day. Pediatrics.Vol.117,pp.e387-95 (2006)

[17] Hausman KM, Mandel D, Domani KA, Mimouni FB, Shay V, Marom R, et al.: The effect of advanced maternal age upon human milk fat content. Breastfeed Med. Vol.8(1), pp.116-9 (2013)

[18] Lonnerdal B, Erdmann P, Thakkar SK, Sauser J, Destaillats F.: Longitudinal evolution of true protein, amino acids and bioactives proteins in breast milk: A developmental perspective. J.Nutr. Biochem. Vol.41, pp.1-11 (2017)

[19] Chang N, Jung JA, Kim H, Jo A, Kang S, Lee SW, et al.: Macronutrient composition of human milk from Korean mothers of full term infants born at 37-42 gestational weeks. Nutrition Research and Practise.Vol.9(4), pp.433-8 (2015)

[20] Mandel D, Lubetzky R, Dollberg S, Barak B, Mimouni FB.: Fat and energy contents of expressed human breast milk in prolonged lactation. Pediatr.Vol.116(3),pp.e432-5 (2005)

[21] Nikniaz L, Mahdavi R, Arefhoesseini SR, Sowti KM.: Association between fat content of breast milk and maternal nutritional status and infants' weight in Tabriz, Iran. Mal J Nutr.;Vol.15(1), pp.37-44 (2009) 